\title{
Spatial variability of deep scattering layers shapes the Bahamian mesopelagic ecosystem
}

\author{
Mei Sato ${ }^{1, *}$, Kelly J. Benoit-Bird ${ }^{1,2}$ \\ ${ }^{1}$ College of Earth, Ocean, and Atmospheric Sciences, Oregon State University, 104 CEOAS Admin Bldg., Corvallis, OR 97331, USA \\ ${ }^{2}$ Monterey Bay Aquarium Research Institute, 7700 Sandholdt Road, Moss Landing, CA 95039, USA
}

\begin{abstract}
Deep scattering layers (DSLs) play an important role in pelagic food webs, serving as a vehicle for transferring energy between productive surface waters and the deep sea. We explored the spatial dynamics of DSLs off the Bahamas in shaping oligotrophic ecosystems. We compared 2 areas known to be important foraging habitats for a deep-diving predator, Blainville's beaked whales: the Tongue of the Ocean (TOTO), an oceanographically isolated habitat, and the waters off Abaco Island, an oceanographically connected habitat. Using ship-based multifrequency echosounders and direct net sampling, we identified common layer structures characterized by diffuse, broad layers (>100 $\mathrm{m}$ in thickness) observed across the study areas. Within those diffuse layers, we occasionally observed distinctively bounded intense layers ( $20 \mathrm{~m}$ in thickness) located at the upper edges of the DSLs. We found that spatial variability of layer structures shaped the Bahamian ecosystem. By comparing common layer types across the sampling locations, 2 potential mechanisms were identified. The area off Abaco Island was characterized by diffuse layers comprised of larger animals with greater migration distance and biomass than the habitat in TOTO, suggesting that Abaco may transfer more energy between energy-rich surface waters and the deep sea. Within TOTO, habitat most frequently used by beaked whales was characterized by the highest occurrence of intense layers dominated by thinner layers, suggesting such fine-scale structures may increase foraging efficiency by layer predators. Spatial variability of the DSL structures reveals the dynamics of the Bahamian mesopelagic ecosystem, potentially driving the beaked whales through bottom-up control of their prey.
\end{abstract}

KEY WORDS: Deep scattering layers $\cdot$ Spatial variability $\cdot$ Acoustics $\cdot$ Bahamas $\cdot$ Tongue of the Ocean $\cdot$ Abaco Island

\section{INTRODUCTION}

Energy transfer through food webs is a fundamental ecosystem function, affecting community structure (Paine 1966, Pace et al. 1999), productivity and nutrient cycling (Post 2002, Duffy et al. 2005), and ultimately affecting reproductive success of the higher trophic levels including commercially important fish species (Pauly \& Christensen 1995, Ware \& Thomson 2005) and marine mammals (Moline et al. 2004). Organisms comprising the deep scattering layers (DSLs) serve as a vehicle for the transfer of energy between trophic levels (Polis et al. 1997).

\footnotetext{
${ }^{*}$ Corresponding author: msato@coas.oregonstate.edu
}

Repeated, diel vertical movements of these layers serve as a vector connecting productive surface waters and deep waters (e.g. Longhurst 1976). Because zooplankton and micronekton that comprise the DSLs reside at depth during daytime, they serve as important prey resources for animals inhabiting deep waters. Combined with fluid advection, DSL movements can acquire a horizontal component that connects different habitats (Wroblewski 1982, Boehlert \& Mundy 1988) and even maintains populations at remotely located ecosystems such as seamounts (Rogers 1994). Because DSLs are a critical link in pelagic food webs, resolving their structure

(C) The authors 2017. Open Access under Creative Commons by Attribution Licence. Use, distribution and reproduction are unrestricted. Authors and original publication must be credited. 
and dynamics is important to quantify the magnitude of habitat coupling and to assess their role in shaping ecosystems.

DSLs are a ubiquitous feature of the worlds' oceans including oligotrophic waters (Hazen \& Johnston 2010, Irigoien et al. 2014, Ariza et al. 2016) and are recognized as one of the key characteristics of whale foraging regions (Hazen et al. 2011, Abecassis et al. 2015). Oligotrophic ecosystems are characterized by high turnover rates and low biomass of phytoplankton, resulting in low carbon flux from the upper mixed layer due to sinking particles (Legendre \& Le Fevre 1991, Agawin et al. 2000, Marañón et al. 2001). In such ecosystems where direct, carbon-flux pathways are limited, the role of DSLs is likely more significant than in other ecosystems in mediating energy in the form that can be utilized by higher trophic level organisms. Despite their importance, our understanding of DSL dynamics in oligotrophic ecosystems is limited to simple metrics such as layer depth, intensity, and total biomass. Although shipbased active acoustic surveys provide high spatial resolution, commonly used data processing methods that integrate or average acoustic backscatter over the water column have limited fine-scale characterizations of the DSLs.

Fine-scale variability in biological aggregations plays an important role in driving ecosystem functions in the ocean. Heterogeneity of planktonic organisms affects the distributions of their predators such as zooplanktivorous fishes and seabirds (Kotliar \& Wiens 1990, Polis et al. 1997). Such spatial coupling does not only occur between predators and prey, but is also observed across the food web. Aggregations of top predators, including large predatory fish, seabirds, and marine mammals, are commonly observed at regions of enhanced primary and secondary productivity (Young et al. 2001, Seki et al. 2002, Bost et al. 2009). Spatial overlap between lower trophic organisms and top predators, without direct linkages of predator-prey interactions, suggests that the top predators may be able to identify locations of significant variability in biological aggregations.

We predict that fine-scale variability in DSLs drives top predator distributions in oligotrophic ecosystems via their role of energy transport between more productive surface waters and the deep sea. We examined the spatial variability of DSL dynamics off the Bahamas, where the DSLs are located at depth during daytime and exhibit diel vertical migration toward shallower depths at night. We compared 2 areas known to be important foraging habitats for one group of deep-diving top predators, beaked whales. Tongue of the Ocean (TOTO) is an important habitat for Blainville's beaked whales Mesoplodon densirostris (McCarthy et al. 2011, Tyack et al. 2011). Detailed habitat usage by beaked whales within TOTO has been historically monitored using combinations of cabled hydrophones and visual observations. These observations have identified significant and persistent spatial variability in preferred foraging habitat within TOTO (Moretti et al. 2006, McCarthy et al. 2011, Claridge 2013). DSL characteristics in these areas of TOTO were compared with the waters off Abaco Island, a nearby region where the Blainville's beaked whales exhibit higher reproduction rates relative to their populations in TOTO (Claridge 2013). Based on long-term records of beaked whales' habitat use (McCarthy et al. 2011, Tyack et al. 2011, Claridge 2013), we employed a biologically guided blocked sampling design to unravel heterogeneity in lower trophic levels, which is currently understudied off the Bahamas.

\section{MATERIALS AND METHODS}

\section{Study site and survey design}

TOTO is a deepwater basin located on the east of Andros Island in the Bahamas (Fig. 1), with the only entrance to the basin located at the north. It is bounded on 2 sides by very shallow waters, while the maximum depths exceed $2000 \mathrm{~m}$. In TOTO, beaked whales are repeatedly exposed to high levels of military activities, including sonar, which have been shown to result in rare mass strandings and likely more frequent population level reductions in fitness (Fernández et al. 2005, Cox et al. 2006, Claridge 2013). Field sampling was conducted in 4 zones within TOTO based on the long-term observations of foraging behavior of Blainville's beaked whales using the Atlantic Undersea Test and Evaluation Center (AUTEC) hydrophone recordings and visual surveys (McCarthy et al. 2011, Tyack et al. 2011, Claridge 2013): the West zone as a frequently used habitat, the East zone as a less-commonly used habitat within the AUTEC range, and the North and South zones as immediately adjacent areas to the AUTEC range and likely used as refuge during the navy sonar exercises (Tyack et al. 2011). Data from these sampling zones were compared with the region approximately $144 \mathrm{~km}$ to the north of the range, southwest of the island of Abaco, which has been identified as a less disturbed area for beaked whale populations with a greater abundance of juveniles 


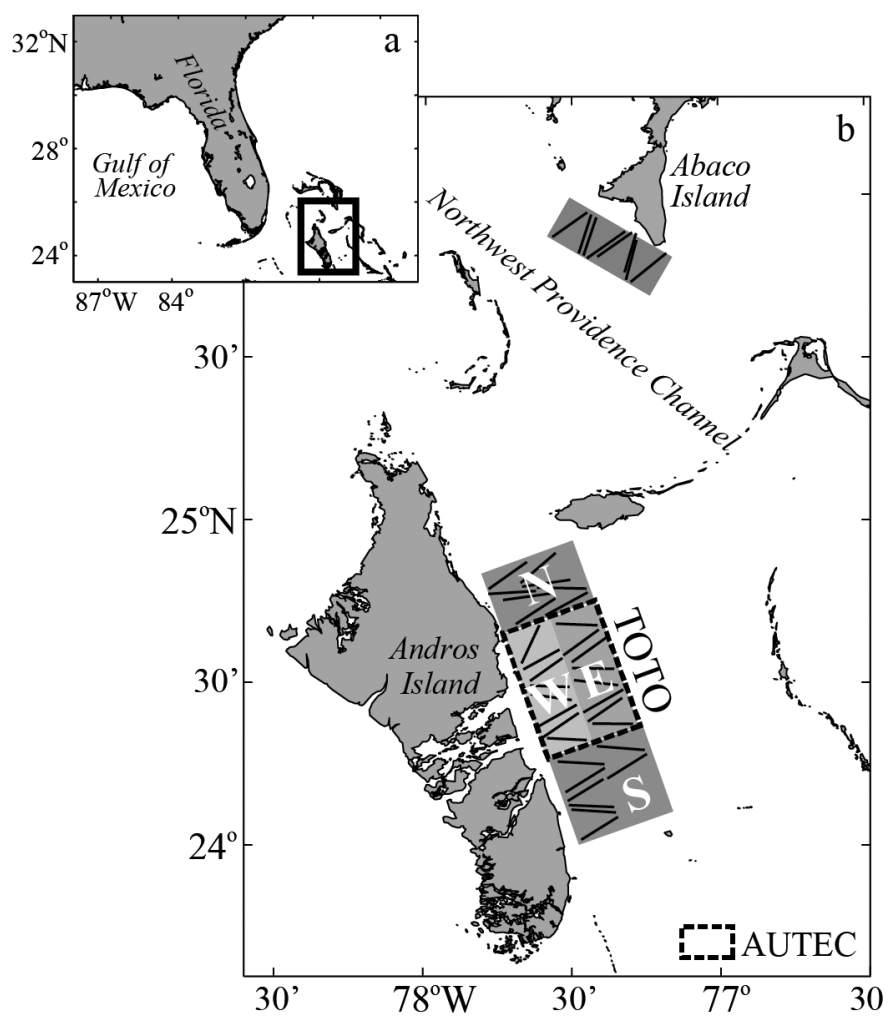

Fig. 1. (a) Study site located in the Bahamas. (b) Sampling zones in the Tongue of the Ocean (TOTO) off the eastern coast of Andros Island and the waters off Abaco Island. TOTO was divided into North, West, East, and South zones. The US Navy's Atlantic Undersea Test and Evaluation Center (AUTEC) range, encompassing the West and East zones, is shown by the dashed line. Each sampling zone had 8 transects shown by the thin solid lines

compared to the populations in TOTO (Claridge 2013). Each area was sampled using eight 16-km long transects, allowing us to examine spatial variability of DSLs.

\section{Data collection and analysis}

Ship-based sampling was conducted within TOTO and off Abaco Island during July 2-14, 2015. Timing of the sampling was decided based on the long-term visual surveys, showing increased sightings of the beaked whales during the summer months (Claridge 2013). Simultaneous measurements of multifrequency hydro-acoustics, net sampling of zooplankton and mesopelagic fish, and conductivity-temperaturedepth (CTD) profiles were conducted on R/V 'Sharp' during daytime, while acoustic surveys alone were conducted at night. Daytime surveys were conducted on all transects, with 2-4 pseudo-randomly chosen transects each day to minimize the effects of time within the survey period on the results. Night surveys were conducted for 4-6 transects in each sampling zone, typically immediately following the daytime survey in the same area. Vessel speed during the acoustic surveys was $3.5-4.8$ knots $\left(1.8-2.5 \mathrm{~m} \mathrm{~s}^{-1}\right.$ ), except at the beginning of each transect during daytime when speed was between 1.5-4.3 knots (0.8-2.2 $\left.\mathrm{m} \mathrm{s}^{-1}\right)$ to accommodate simultaneous net sampling.

\section{Oceanographic data}

To characterize spatial variability of water properties, we collected vertical profiles of temperature and conductivity (SBE 911plus; Sea-Bird Electronics), oxygen (SBE 43; Sea-Bird Electronics), and fluorescence (WET Labs ECO FL). The profiles to a maximum depth of $600 \mathrm{~m}$ were taken during daytime at the start of 4 randomly chosen transects per sampling zone. CTD and oxygen data were aligned to correct for instrument lags and edited for loops before raw data were converted to variables of interest using factory calibrations. Each profile was averaged into $1 \mathrm{~m}$ depth bins. Physical properties of the sampling areas (Abaco vs. TOTO) were examined using a temperature-salinity (T-S) diagram. Statistical differences in integrated fluorescence values over 6-250 m between sampling areas and the 4 sampling zones within TOTO (North, West, East, and South) were tested using a Mann-Whitney $U$-test and a KruskalWallis test, respectively.

\section{Acoustic data}

Acoustic backscatter data were collected using Simrad EK60s operating at $38 \mathrm{kHz}\left(12^{\circ}\right.$ split-beam), and 70,120 , and $200 \mathrm{kHz}$ ( $7^{\circ}$ split-beams). Transducers were deployed downward-looking at $2 \mathrm{~m}$ below the vessel's keel, corresponding to $5 \mathrm{~m}$ below the surface. Transducers were mounted as close to each other as possible in order to maximize the spatial overlap of the beams. The system ran continuously at maximum ping rate (typically $0.85-2$ pings $\mathrm{s}^{-1}$ ) with a pulse duration of $1024 \mu \mathrm{s}$ and a vertical resolution of $20 \mathrm{~cm}$. All echosounders were calibrated using a standard sphere method (Demer et al. 2015) before the field survey. Because the DSLs were typically located at approximately 350-600 m depth, only data collected at 38 and $70 \mathrm{kHz}$ were used in this analysis. 
Pre-processing. Acoustic data were pre-processed using Echoview (version 6.1; Echoview Software Pty Ltd). Data within $3 \mathrm{~m}$ of the transducers (shallower than $8 \mathrm{~m}$ depth) were removed from analyses to eliminate near-field transducer effects and to reduce backscatter from surface bubbles. The echosounderdetected bottom was visually inspected, corrected if necessary, and data within $2 \mathrm{~m}$ of the bottom were removed from analyses. Background noise was removed using a technique developed by De Robertis \& Higginbottom (2007) with a minimum signal-tonoise ratio of $10 \mathrm{~dB}$ and maximum noise threshold of $-125 \mathrm{~dB}$ re $1 \mathrm{~m}^{-1}$. Due to the increase in background noise with depth, acoustic data analysis was limited to the upper $600 \mathrm{~m}$ of the water column, where the effect of background noise was minimal. An average of all CTD downcasts collected over the upper $600 \mathrm{~m}$ of water column was used to estimate sound speed (Mackenzie 1981) and absorption coefficients (Ainslie \& McColm 1998), which were then used to calculate volume backscattering strength $\left(S_{\mathrm{v}}\right.$ dB re $1 \mathrm{~m}^{-1}$ ) and target range. Based on the range of sound speed values measured, use of a constant sound speed could introduce a maximum of $9 \mathrm{~m}$ of error into the vertical position of scattering features at $600 \mathrm{~m}$ range. All data were visually inspected for anomalies such as false bottom, noise spikes, and backscatter signals likely from marine mammals, which were removed. All data were smoothed by applying 5 pings $\times 5$ bins (corresponding to 5-15 $\mathrm{m}$ horizontal $\times 1 \mathrm{~m}$ vertical) running averages to account for the stochastic nature of volume backscattering amongst frequencies (Simmonds \& MacLennan 2005), then exported from Echoview to Matlab (Mathworks, R2013a) for further analysis.

Scattering layer characterization. We characterized scattering layers during both day and night surveys. We used the data collected during the period without any observable diel vertical migration behavior in the water column: daytime defined from $3 \mathrm{~h}$ after sunrise through $3 \mathrm{~h}$ before sunset, and nighttime defined from $1 \mathrm{~h}$ after sunset through $1 \mathrm{~h}$ before sunrise. Sunrise and sunset times at the study site were obtained from the US Naval Observatory (http://aa.usno.navy. mil/data/index.php). Each data set was further smoothed by applying 15 pings $\times 15$ bins (corresponding to $14-44 \mathrm{~m}$ horizontal $\times 3 \mathrm{~m}$ vertical) running medians to remove intermittent regions of high backscatter intensity, while smoothing the edges of continuous features to facilitate layer detection. Based on 2 vertically separated scattering layer structures, we characterized surface scattering layers (SSLs) located at shallower than $300 \mathrm{~m}$ and DSLs located at deeper than $350 \mathrm{~m}$.

We identified 2 types of layer structures based on the further smoothed data (15 pings $\times 15$ bins running medians; Fig. 2a). Most commonly, layers were diffuse and broad (Fig. 2b). Within those diffuse layers, we occasionally observed distinctively bounded intense layers located at the upper edges of DSLs (Fig. 2c). Diffuse layers were defined by applying $100 \mathrm{~m}$ running medians vertically at each ping. The
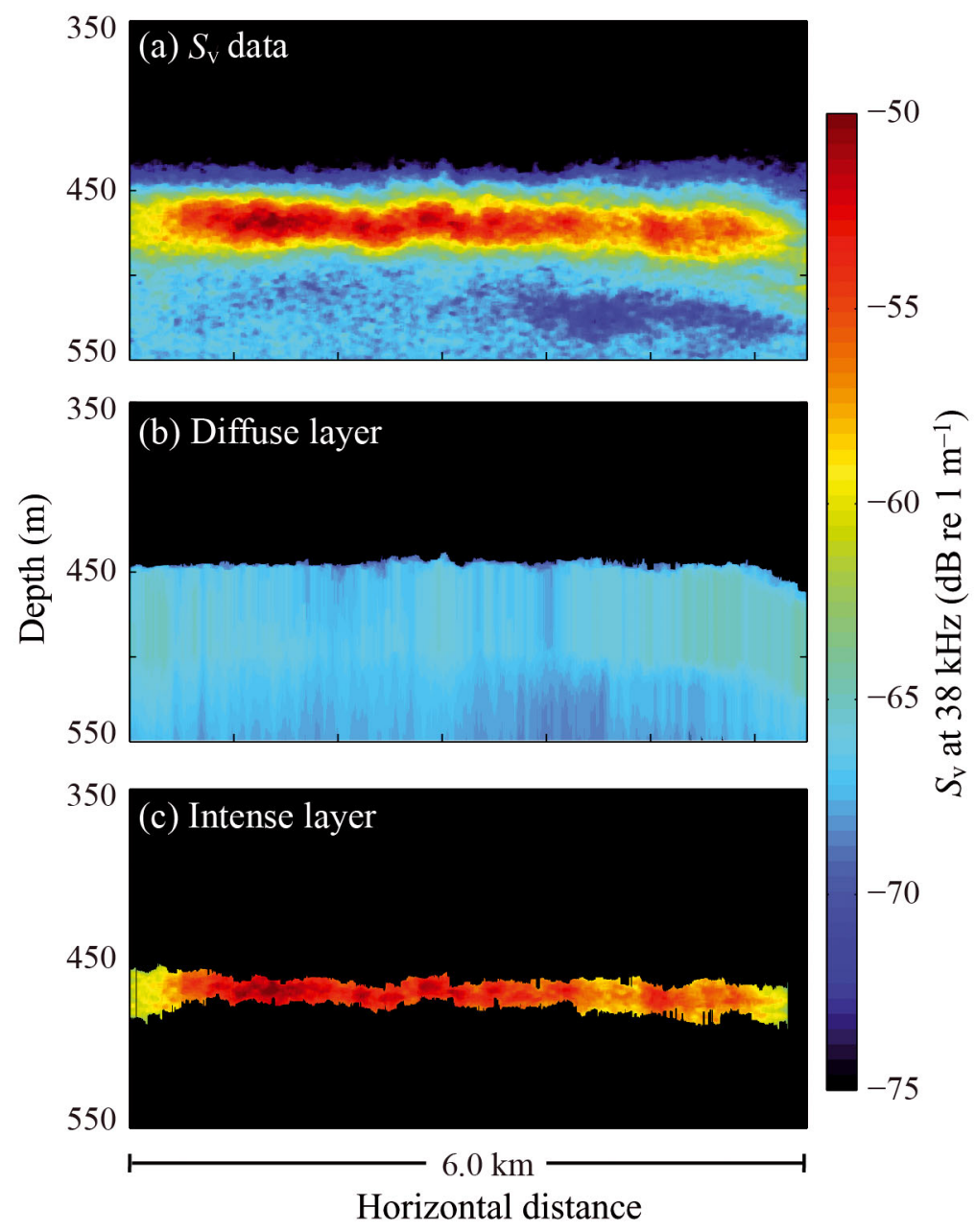

Fig. 2. Representative echograms of deep scattering layers. (a) Smoothed volume backscattering strength $\left(S_{\mathrm{v}}\right)$ data with 15 pings $\times 15$ bins, (b) the diffuse layer, defined as the $100 \mathrm{~m}$ running medians in the vertical dimension, and (c) the intense layer, defined as local maxima. Detected layer structures in (b) and (c) were characterized as layer peaks $\pm 3 \mathrm{~dB}$ 
size of the median filter was chosen to avoid the contamination from the intense layers. Thin, intense layers, which were local maxima located within the diffuse layers, were identified after removal of the diffuse layers to avoid overestimation of the intense layers. Both diffuse and intense layers were characterized at $38 \mathrm{kHz}$ because the intense layers were clearly observed at $38 \mathrm{kHz}$ while the diffuse layers appeared at both 38 and $70 \mathrm{kHz}$. We used a series of criteria to identify 2 layer structures following Shroyer et al. (2014). (1) Both layers were required to exceed the $S_{\mathrm{v}}$ threshold of $-78 \mathrm{~dB}$ re $1 \mathrm{~m}^{-1}$, excluding the noise from analysis. (2) Layer peak was defined as maximum $S_{\mathrm{v}}$, exceeding the threshold of $-75 \mathrm{~dB}$ re $1 \mathrm{~m}^{-1}$ for the diffuse layers and $-60 \mathrm{~dB}$ re $1 \mathrm{~m}^{-1}$ for the intense layers. For the intense layers, the maximum values identified in the diffuse layerremoved data were located on the original $S_{\mathrm{v}}$ (i.e. before removal of diffuse layer was applied). (3) The depth of the diffuse and intense layers was characterized by the depth of the layer peak, and the upper and lower edges of the layers were defined by a $3 \mathrm{~dB}$ decrease from the maximum amplitude. Due to the $600 \mathrm{~m}$ limit in data analysis combined with the $100 \mathrm{~m}$ vertical filtering, the minimum depth of the upper edges of SSLs was limited to $60 \mathrm{~m}$ and the maximum depth of the lower edges of DSLs to $550 \mathrm{~m}$. Frequency response of each layer type was determined by taking the difference of the detected layer integrated over the area between the upper and lower edges at 38 and $70 \mathrm{kHz}$. Nautical area scattering coefficient (NASC; $\mathrm{m}^{2} \mathrm{nmi}^{-2}$ ), which is a linear measure of integrated backscatter, was calculated over the area between the upper and lower edges of the detected layers. For intense layers, the frequency of occurrence was estimated by the percentage of pings identified as the intense layers along the entire transects, and patch size was estimated by calculating the horizontal distance of continuously observed intense layers.

To determine possible effects of sampling areas and zones, observed layer characteristics including depth of layer peak, upper- and lower-edge depths, layer peak $S_{\mathrm{v}}$, frequency differences, and NASC values were averaged over the transects within each sampling zone. Statistical differences in the layer characteristics between sampling areas and zones were tested for using a Mann-Whitney $U$-test and a Kruskal-Wallis test, respectively. Spatial variability of intense layers was further characterized in terms of their frequency of occurrence, strength, layer thickness, and horizontal scales. Due to the shortening of the available data sets to avoid diel vertical migration periods, only transects having more than $50 \%$ of the original length were considered here. The entire length of transects in each sampling zone was combined for the cumulative distribution function.

\section{Net samples}

DSLs detected by the echosounders were sampled with an Isaacs-Kidd midwater trawl $\left(4 \mathrm{~m}^{2}\right.$ mouth opening) fitted with $1 \mathrm{~mm}$ mesh in the cod end towed at a vessel speed of $\sim 4$ knots $\left(2.1 \mathrm{~m} \mathrm{~s}^{-1}\right)$. A total of 20 tows were conducted during daytime with 4 tows per sampling zone. The target depth of each tow was selected to sample high concentrations of acoustic backscatter. Trawl depth was monitored and directed using a real-time remote pressure sensor (PI32; Kongsberg Maritime) attached to the headrope of the net. The net was towed horizontally at a depth of 350-600 m, depending on the DSL depth, for a total duration of $25 \mathrm{~min}$ and then hauled back at a rate of $50 \mathrm{~m}$ of wire per minute. The net, which was dark in color, towed at relatively high speeds, and with minimal hardware to create a head wake, effectively sampled organisms with body lengths between 1 and $35 \mathrm{~cm}$. With the exception of gelatinous organisms, which were classified and discarded on board, net samples were immediately preserved in $4 \%$ formalin in seawater buffered with sodium borate. Since neither acoustics nor trawls quantitatively sample fragile gelatinous organisms (Davison et al. 2015), their contributions to the DSLs were not examined here. In the laboratory, all of the net contents were identified to species under a dissecting microscope, and a subsample of each species (up to 30 individuals) was measured for animal length. Fish were measured for standard length, while euphausiids and shrimps were measured from the posterior base of the eye stalk to the end of the last abdominal segment (Standard Length 3 in Mauchline 1980a, as cited by Ashjian et al. 2004). Total body length along the longest axis was measured for all other zooplankton taxa. All samples were standardized by the filtered volume estimated based on the average vessel speed during the tow at the target depth, duration of the tow, and the mouth opening of the trawl. Density of zooplankton and fish were assessed as a function of targeted layer types and sampling areas using a non-parametric multivariate analysis of variance (MANOVA; Anderson 2001). Statistical differences in density and length of abundant taxonomic groups (bristlemouth larvae, other fish, euphausiids, Oplo- 
phorus sp., other shrimps, pteropods) between targeted layer types and sampling areas were tested for using a Mann-Whitney $U$-test. Because the net tows were collected within diffuse layers, intense layers, or both layers, only net samples collected within diffuse $(n=8)$ or intense layers $(n=3)$ were used to examine the effect of layer types.

\section{RESULTS}

\section{Environmental conditions}

Salinity profiles differed between Abaco and TOTO (Fig. 3), while temperature, density, and oxygen profiles were very similar across the sampling zones. Salinity profiles off Abaco were relatively consistent at 36.5-36.7 at upper $370 \mathrm{~m}$ and gradually decreased to 35.7 at $600 \mathrm{~m}$. In TOTO, salinity in the surface mixed layer located at upper $50 \mathrm{~m}$ was 36.7, increasing to a maximum of 37 at $100-200 \mathrm{~m}$ then gradually decreasing to 35.7 at $600 \mathrm{~m}$. Temperature at both areas was approximately $29^{\circ} \mathrm{C}$ in the surface mixed layers and gradually decreased to about $13^{\circ} \mathrm{C}$ at $600 \mathrm{~m}$. Density, more sensitive to changes in temperature than salinity, largely mirrored the temperature patterns. Oxygen was $6.3 \mathrm{mg} \mathrm{l}^{-1}$ at the surface and gradually increased to $8.4 \mathrm{mg} \mathrm{l}^{-1}$ at $600 \mathrm{~m}$ in all sampling zones. Fluorescence maxima of $0.3 \mathrm{mg} \mathrm{m}^{-3}$ occurred at approximately $95 \mathrm{~m}$, and its value decreased toward 0 at $160 \mathrm{~m}$ in TOTO, while the maxima occurred slightly deeper at $109 \mathrm{~m}$ in Abaco with its value decreasing toward 0 at $250 \mathrm{~m}$. Integrated fluorescence values in the upper $250 \mathrm{~m}$ in Abaco $(31.8 \pm 1.2 \mathrm{mg}$ $\mathrm{m}^{-2}$ ) were significantly higher than those in TOTO $\left(22.9 \pm 3.7 \mathrm{mg} \mathrm{m}^{-2}, \mathrm{p}=0.003\right)$, while there was no significant effect of sampling zone within TOTO $\left(\mathrm{df}=3, \chi^{2}=\right.$ 4.88, $\mathrm{p}=0.18)$.

\section{Scattering layer characteristics}

There were 2 types of layer structures observed in the Bahamian ecosystem. Diffuse layers were a common structure observed in all sampling zones, within both SSLs and DSLs, and during both day and night (Fig. 4). Intense layers, on the other hand, showed spatial variability. In TOTO, intense layers were occasionally observed within DSLs during daytime and migrated to a shallower depth at night. In Abaco, few intense layers were present within SSLs during the day and night, while no intense layer was observed within DSLs. Daytime DSLs were characterized using both acoustics and direct net sampling, while other scattering layers were only observed by acoustics.

\section{Diffuse vs. intense layers}

To examine the differences between diffuse and intense layers, we characterized the daytime DSLs where simultaneous sampling of acoustics and net tows was available. Diffuse layers in Abaco and TOTO began at an average of $432 \mathrm{~m}$ depth and continued at least to the range limit of the ship-based acoustic observations (Fig. 4). Intense layers were only observed within TOTO, located just below the upper edges of the diffuse layers, maintaining their depths within the diffuse layers $(y=1.06 x+0.84$, where $x$ is upper-edge depth of diffuse layers and $y$ is layer peak depth of intense layers, $r^{2}=0.79$, number of data points $=27112$ ). Layer thickness of intense layers was similar across the sampling zones with the average values ranging between 18.3 and $22.4 \mathrm{~m}$. Diffuse and intense layers have distinct acoustic charac-

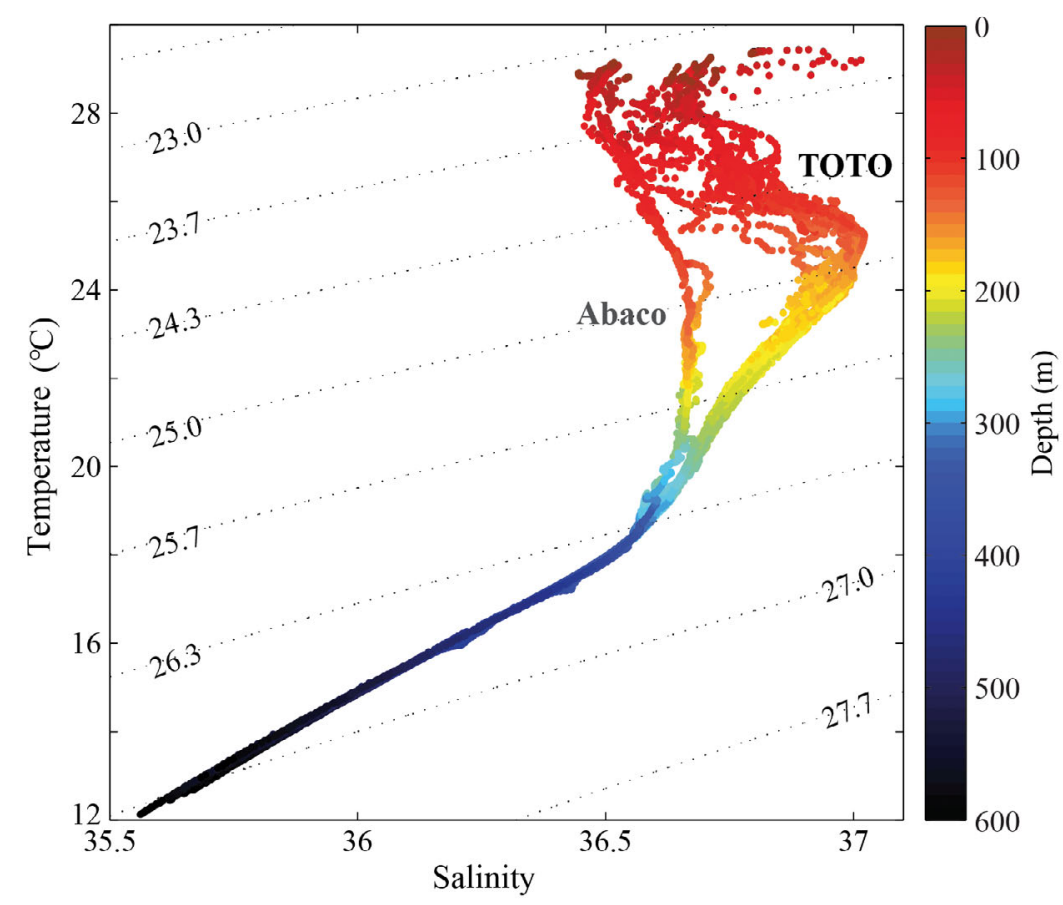

Fig. 3. Temperature-salinity diagram of CTD data collected in the Tongue of the Ocean (TOTO) and off Abaco Island with corresponding potential density values 


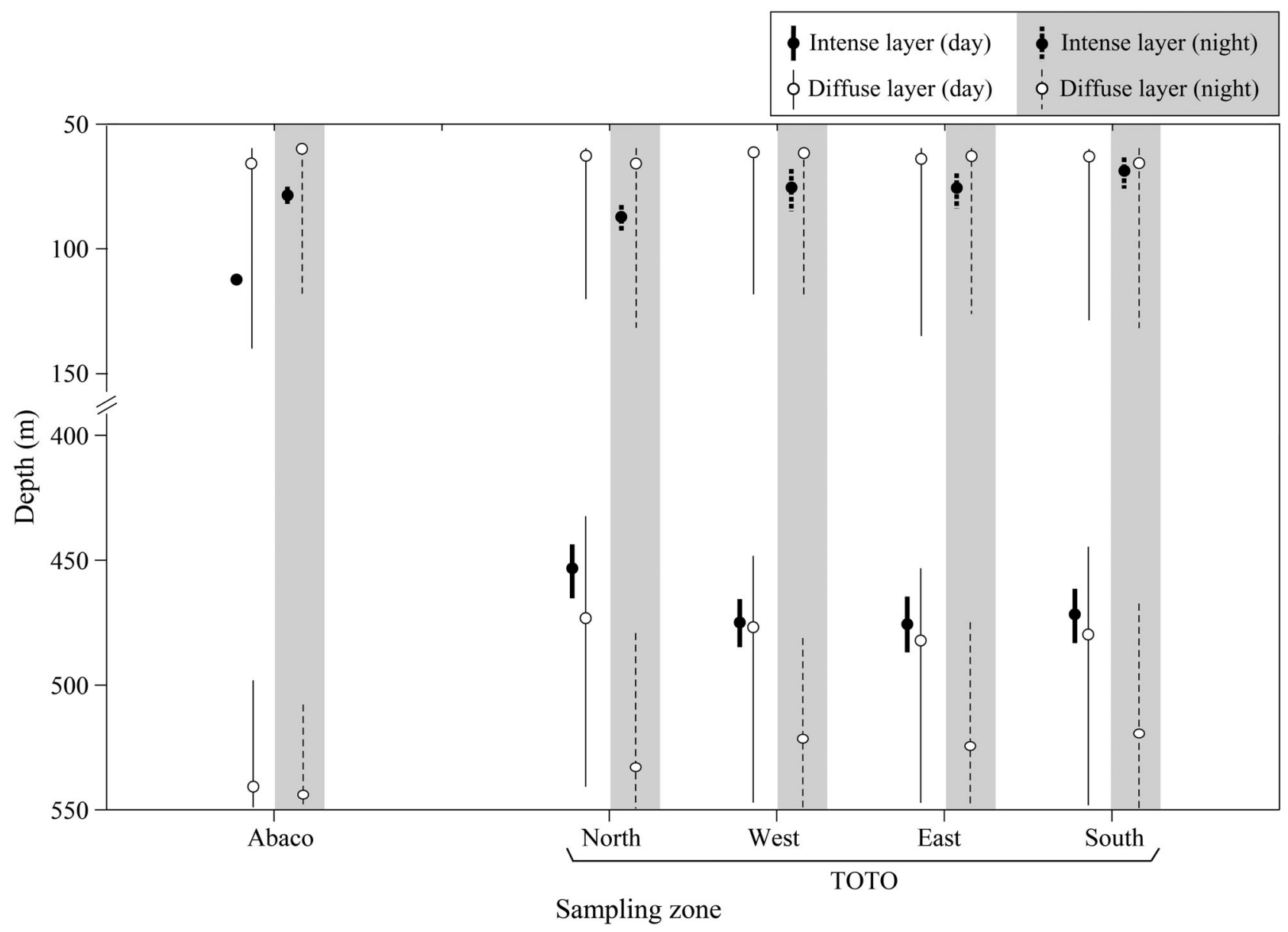

Fig. 4. Depth of diffuse (thin lines) and intense layers (thick lines) observed within surface and deep scattering layers averaged over the entire transects within each sampling zone. Circles show the depth of the layer peak; lines show upper and lower edges of the detected layers. TOTO: Tongue of the Ocean

teristics where diffuse layers were characterized by weaker peak $S_{\mathrm{v}}$ and lower $\Delta S_{\mathrm{v} 38-70 \mathrm{kHz}}$ than those in intense layers (Fig. 5). These acoustic characteristics corresponded to the differences in taxonomic group compositions of the 2 layer types. There was a significant effect of layer type on the density of abundant taxonomic groups (Table 1). Density of swimbladderbearing bristlemouth fish larvae was significantly higher in the intense layers $(p<0.05)$, while the density of euphausiids was higher in the diffuse layers $(p=0.01$; Fig. 6). There was no significant effect of layer type on the density of other fish, Oplophorus sp., other shrimps, pteropods (Fig. 6), and length of all taxonomic groups ( $p>0.3$ for all comparisons).

\section{Diffuse layers: Abaco vs. TOTO}

To examine differences in diffuse layers between sampling areas (Abaco vs. TOTO), we focused on characterizing the daytime DSLs using both acoustics

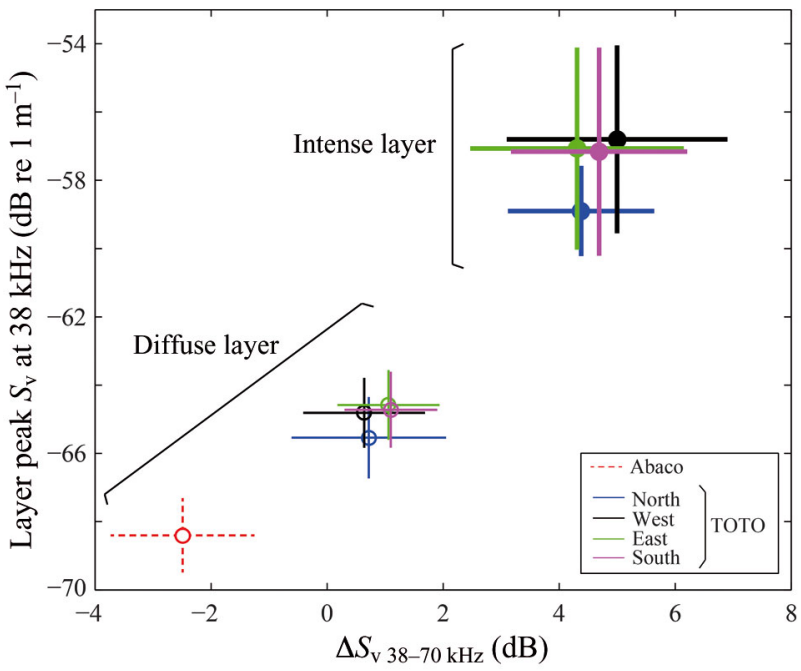

Fig. 5. Layer peak volume backscattering strength $\left(S_{\mathrm{v}}\right)$ values and $\Delta S_{\mathrm{v}} 38-70 \mathrm{kHz}$ of the diffuse (thin lines) and intense layers (thick lines) observed within deep scattering layers during daytime. Circles show the mean values calculated over the entire transects within each sampling zone; error bars show SD. TOTO: Tongue of the Ocean 
Table 1. Summary of non-parametric multivariate analysis of variance (MANOVA), testing the effects of layer type and sampling area on the community composition of deep scat-

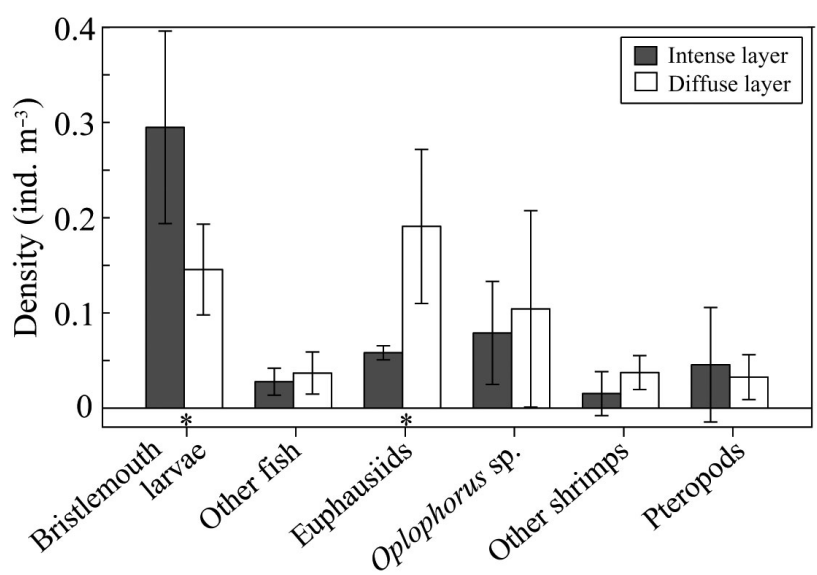

Fig. 6. Median density of major taxonomic groups collected within intense and diffuse layers. Error bars show SD. *Significant effects by the Mann-Whitney $U$-test $(p<0.05)$

and net samples. Depths of the upper edges and peaks of the diffuse layers were located significantly deeper in Abaco than in TOTO (Fig. 4; p < 0.001). Lower edges of the diffuse layer were the same across all sampling zones due to the analysis limit. Acoustic characteristics showed that diffuse layers in Abaco were $\sim 3 \mathrm{~dB}$ lower in peak $S_{\mathrm{v}}$ values and $\sim 3.5 \mathrm{~dB}$ lower in $\Delta S_{\mathrm{v}} 38-70 \mathrm{kHz}$ values than those tering layers

\begin{tabular}{lrccr} 
Source & df & MS & $F$ & \multicolumn{1}{c}{ p } \\
\hline Layer type & 1 & 0.012 & 3.279 & $<0.05$ \\
Sampling area & 1 & 0.004 & 1.035 & 0.41 \\
Residuals & 8 & 0.004 & & \\
Total & 10 & & & \\
\hline
\end{tabular}

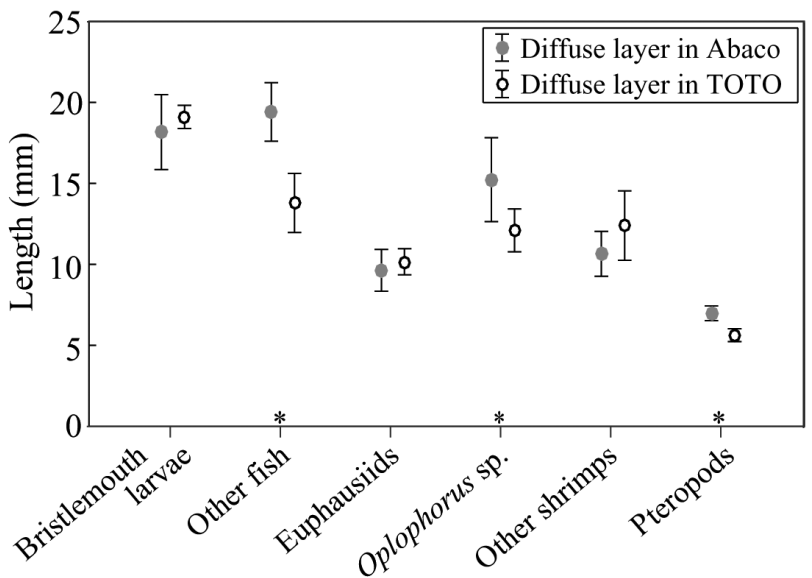

Fig. 7. Median length of major taxonomic groups collected within diffuse layers in Abaco and Tongue of the Ocean (TOTO). Error bars show SD. * Significant effects by the Mann-Whitney $U$-test $(\mathrm{p}<0.05)$

observed in TOTO (Fig. 5). These acoustic characteristics corresponded to the size differences of major taxonomic groups comprising these layers. Length of other fish (e.g. myctophids, hachetfish, pufferfish), Oplophorus sp., and pteropods was significantly larger in Abaco than in TOTO ( $p=0.03$; Fig. 7). There was no significant effect of sampling area on length of bristlemouth larvae, euphausiids, and other shrimps ( $p>0.2$ for all comparisons; Fig. 7), and density of all taxonomic groups (Table 1). Daytime NASC values integrated between the upper and lower edges of the diffuse layers were significantly higher in TOTO than in Abaco (Fig. 8a; p < 0.001).

Diffuse layers within DSLs were partially shifted toward shallower depths at night, resulting in deepening of the upper-edge and layer peak depths of the DSLs at all sampling zones relative to the daytime depths (Fig. 4) with statistically significant changes

\section{(b) Surface scattering layer}

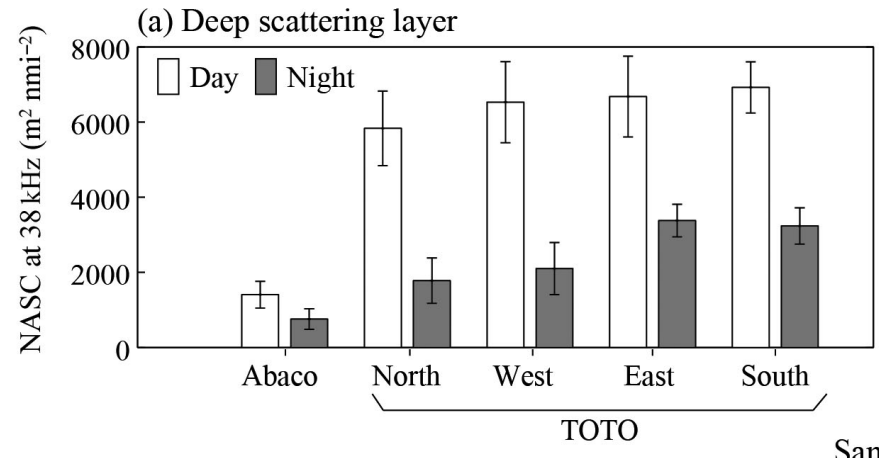

Sampling zones

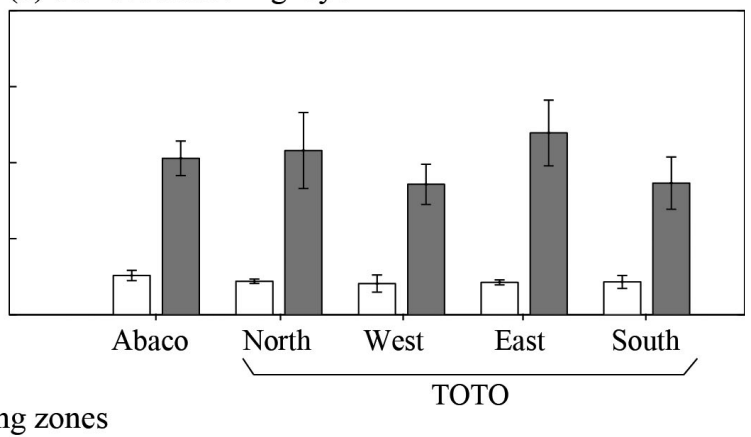

Fig. 8. Nautical area scattering coefficient (NASC) values of diffuse layers of the (a) deep scattering layers and (b) surface scattering layers during day and night at $38 \mathrm{kHz}$, integrated between upper- and lower-edge depths. Bar graphs show average of NASC values of all transects at each sampling zone; error bars show SD. TOTO: Tongue of the Ocean 
in the North, West, and South zones $(p<0.03$ for all comparisons), while changes in the East zone ( $\mathrm{p}=$ 0.06) and Abaco ( $p=0.07)$ were not significant. In Abaco, little difference was observed between daytime and night NASC values in DSLs (Fig. 8a; $\mathrm{p}=$ 0.14 ), while a significant increase in night NASC values in SSLs compared to daytime values $(p=0.04)$ was detected. In TOTO, a significant increase in night NASC values of SSLs compared to daytime values $(\mathrm{p}<0.04)$ corresponded to a significant decrease in night NASC values of DSLs compared to daytime values $(p<0.02)$, except in the East zone $(p=0.06)$. There was no significant effect of sampling area (Abaco vs. TOTO) on night NASC values in SSLs ( $p=$ $0.67)$.

Intense layers: variability within TOTO

To examine the differences in intense layers between sampling zones, we focused on characterizing the intense layers located in DSLs during daytime and in SSLs at night within TOTO as these layers were inconsistently present in Abaco. In daytime DSLs, the frequency response of the intense layers was similar across the sampling zones (Fig. 5; df $=3$, $\left.\chi^{2}=2.78, p=0.43\right)$. Due to the small number of net tows that successfully targeted the intense layers ( $\mathrm{n}=3$ ), no statistical test was conducted to examine the effect of the sampling zone on the density and length of the taxonomic groups comprising these scattering layers.

Although the average characteristics of the intense layers were similar across the sampling zones, we observed spatial variability in the intense layers in terms of (1) frequency of occurrence, (2) layer strength, (3) layer thickness, and (4) patch size or horizontal extent (Fig. 9). Frequency of occurrence of intense layers in daytime DSLs varied between sampling zones: $16.2 \%$ in the North, $63.9 \%$ in the West, $47.6 \%$ in the East, and $34.1 \%$ in the South. Occurrence of high NASC values greatly differed within TOTO, with only $5 \%$ of the data exhibiting NASC $>10000 \mathrm{~m}^{2} \mathrm{nmi}^{-2}$ in the North, while $\sim 20 \%$ in the West, East, and South zones (Fig. 10a). Layer thickness varied between sampling zones, with $2.5 \%$ of the data exhibiting a layer thickness greater than $30 \mathrm{~m}$ in the West, while $12-14 \%$ in the North, East, and South zones (Fig. 10b). Lastly, occurrence of the large patch differed within TOTO, with only $2.1 \%$ of the data exhibiting horizontal patch size $>500 \mathrm{~m}$ in the North, while $6-7 \%$ in the West, East, and South zones (Fig. 10c).
At night, intense layers located within the DSLs were shifted toward shallower depths in all sampling zones. Spatial variability in NASC showed similar patterns during day and night, but the NASC values at night were much lower than those during daytime. Frequency of occurrence of intense layers in night SSLs was $16.5 \%$ in the North, $25.0 \%$ in the West, $52.3 \%$ in the East, and $39.2 \%$ in the South zones. Occurrence of high NASC values $\left(>5000 \mathrm{~m}^{2} \mathrm{nmi}^{-2}\right)$ was $3 \%$ in the North, while it was $\sim 11-13 \%$ in the West, East, and South zones, maintaining patterns similar to those observed during daytime. Layers greater than $30 \mathrm{~m}$ in thickness occurred $7 \%$ of the time in the West zone and only $\sim 2-3 \%$ in the North, East, and South zones. Occurrence of patch size greater than $500 \mathrm{~m}$ was less than $1 \%$ in all sampling zones.

In summary, intense layers within the daytime DSLs showed significant differences between sampling zones within TOTO. The North zone was characterized by the lowest occurrence of intense layers, dominated by weaker NASC values and smaller patch sizes compared to the West, East, and South zones. The West zone was distinctively different from the East and South zones with the highest occurrence of an intense layer that was typically thinner. At night in SSLs, intense layer structures were less common and weaker, thinner layers and smaller patch sizes dominated, making the differences in intense layers between sampling zones less distinct.

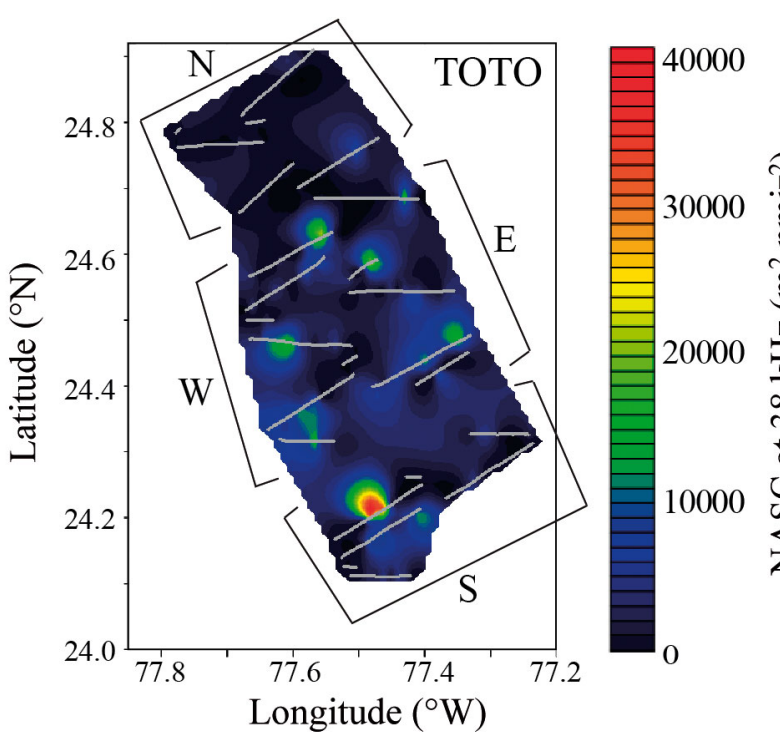

Fig. 9. Interpolated nautical area scattering coefficient (NASC) values of intense layers observed at daytime deep scattering layers at $38 \mathrm{kHz}$, integrated between upper and lower edges of the observed layers. White lines show the transect lines. TOTO: Tongue of the Ocean 


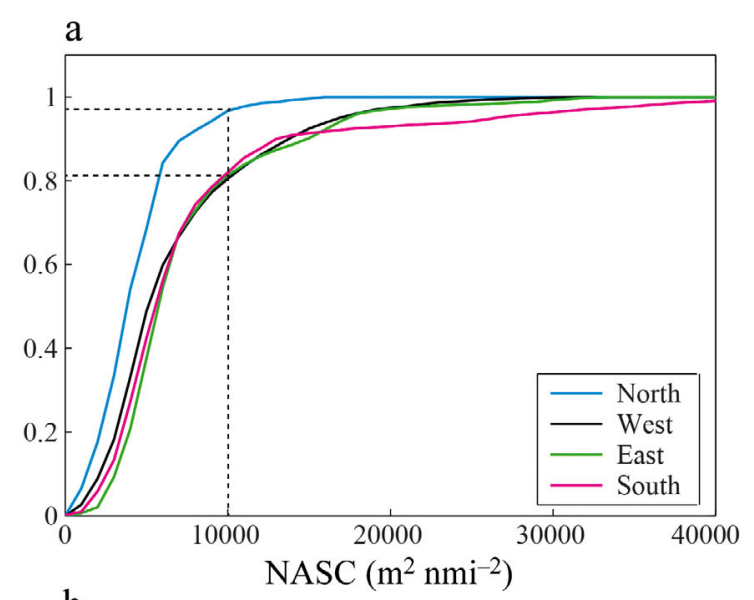

b
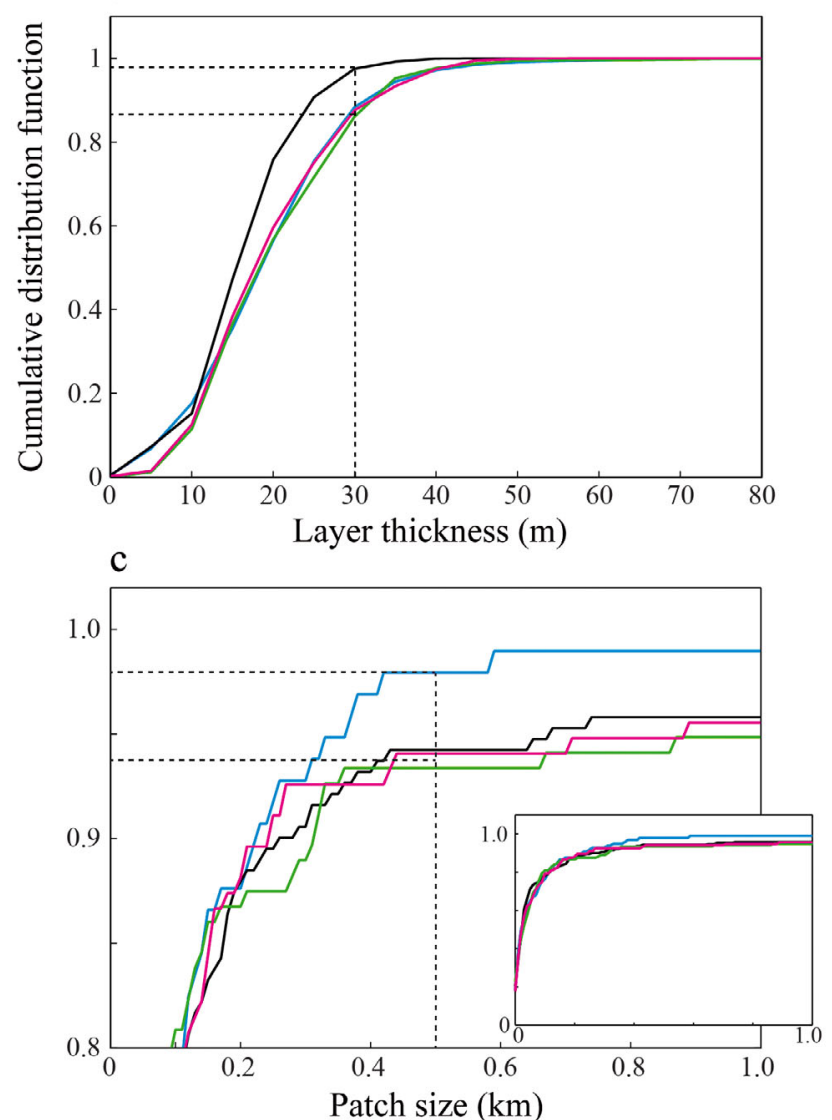

Fig. 10. Cumulative distribution function of (a) nautical area scattering coefficient (NASC) values, (b) layer thickness, and (c) patch size for intense layers of deep scattering layers during daytime. Inset shows the overview, while the larger panel shows the same data magnified on the $y$-axis. Dashed lines are the reference values used to compare 4 sampling zones within the Tongue of the Ocean

\section{DISCUSSION}

We assessed the spatial variability of DSLs in the mesopelagic ecosystem off the Bahamas by examining 2 types of layer structures: diffuse, broad layers
( $>100 \mathrm{~m}$ in thickness) and distinctively bounded intense layers ( $20 \mathrm{~m}$ in thickness). Diffuse layers were observed in all sampling zones with some portions of the layers migrating to shallower depth at night, while intense layers were only observed within TOTO where the entire intense layer migrated upwards at night. Trawl catches of both types of layers observed in daytime DSLs were composed of zooplankton and mesopelagic fishes, with bristlemouth larvae, euphausiids, and Oplophorus sp. being the dominant taxonomic groups. These animals feed on phytoplankton, small zooplankton, and detritus (Mauchline 1980b, Karuppasamy \& Menon 2004, Bernal et al. 2015) and are common prey for the large mesopelagic fishes and cephalopods (Nigmatullin et al. 2001, Choy et al. 2013) that are primary prey for the Blainville's beaked whales (Santos et al. 2001, Hickmott 2005). The constant frequency response throughout the day and coherent movement of these layers support the conclusion that species composition within each layer type remained the same between day and night despite the lack of trawl information at night. Since the dominant animals found in daytime DSLs are known to conduct nocturnal migrations towards the epipelagic layers to feed, they could function as vehicles for energy transport between primary production found near the surface and higher trophic levels found at depth (Benoit-Bird \& Au 2004, Sato et al. 2013, Cohen \& Forward 2016). It is, however, possible that organisms larger than those captured by the trawl were the primary constituents of the DSLs observed. Frame trawls, including the Isaacs-Kidd midwater trawl, were designed to sample mesopelagic organisms that avoid plankton nets (Isaacs \& Kidd 1953, Methot 1986) and have been shown to be effective at collecting samples from the DSLs dominated by shrimps, euphausiids, squids, and myctophids (Karuppasamy et al. 2006, Podeswa \& Pakhomov 2015). However, given the size limitations imposed by the sampling vessel, the trawl used was relatively small, increasing the difficulty in catching fast-swimming organisms due to their net avoidance behavior (Kaartvedt et al. 2012, Davison et al. 2015).

Energy content is an important measure of food quality, affecting efficiency of energy transfer through food webs. We compared the diffuse layer characteristics, which were a common layer type observed across the study region, to address the energy transfer between primary producers and mesopelagic organisms. Significantly higher primary production combined with larger Oplophorus sp., other fish, and pteropods composing diffuse layers in 
Abaco compared to TOTO (Fig. 7) suggests higher energy content in Abaco, thus increasing potential energy transfer across the trophic levels. Importance of the size of mesopelagic organisms in determining the energy content is further supported by the insignificant difference in their density between the 2 sampling areas (Table 1). Diel vertical migration is an important component of the biological pump, where the increase in migration biomass and feeding rate near the surface at night have led to a significant increase in active transport of carbon (Hannides et al. 2009, Steinberg et al. 2012, Podeswa \& Pakhomov 2015). Thus, migration biomass and distance affect the amount of energy transferred and its magnitude, likely playing an important role in controlling ecosystem function. In Abaco, the significant increase in integrated acoustic scattering measured at night relative to that measured during daytime at shallower depths, with no difference in those values for the DSLs between day and night, suggests that migrating organisms originated deeper than the $550 \mathrm{~m}$ range limit of our observations. Therefore, significantly lower integrated acoustic scattering of DSLs in Abaco than in TOTO is likely due to the deepening of the DSLs in Abaco, and does not necessarily indicate lower biomass. In TOTO, on the other hand, the majority of migrating organisms likely originated from the observed DSLs based on the consistent decrease in integrated acoustic scattering of DSLs at night combined with an increase in that measured at shallower depths at night. Size-dependent predation risk (De Robertis et al. 2000) might be a potential driver for the deeper positioning of the DSLs in Abaco than in TOTO, given the significantly larger sizes of some taxa in Abaco than in TOTO (Fig. 7). Greater migration distances and biomass of diffuse layers observed in Abaco indicate stronger coupling between productive surface waters and the deep sea in Abaco than in TOTO. Differences in diffuse layer characteristics between Abaco and TOTO suggest that the amount of energy transferred between surface primary production and mesopelagic communities in deep water is larger in Abaco, potentially leading to the relatively high reproductive success observed for the beaked whales in Abaco (Claridge 2013) through bottom-up control.

One of the potential mechanisms contributing to the observed differences in ecosystem structure is the difference in physical processes between Abaco and TOTO as indicated by the T-S diagram of the upper $300 \mathrm{~m}$ (Fig. 3). General characteristics of higher salinity associated with high temperature in the upper water column are due to high evaporation rates and solar heating during summer months in the Bahamas (Armstrong 1953, Wilson \& Roberts 1995). Loss of moisture from the ocean surface combined with increasing temperature generates density instabilities. In the open ocean, such instabilities are freely re-equilibrated by large-scale oceanographic circulations involving vertical and lateral flow. This mechanism likely applies to Abaco located in Northwest Providence Channel, where maximum current velocities of $\sim 20 \mathrm{~cm} \mathrm{~s}^{-1}$ were observed (Leaman et al. 1995). Within TOTO, equilibration is less likely because the basin is bounded on 2 sides by very shallow waters, making it less susceptible to large-scale physical processes which result in maintenance of the high-salinity water mass. Differences in physical processes in the upper water column may contribute to higher primary production in Abaco than TOTO. The presence of intense layers within DSLs in TOTO, but not in Abaco, was also one of the fundamental differences between the 2 ecosystems, which may also be regulated by physical processes.

The spatial variability of intense layers may play a critical role in determining the amount of energy transferred to higher trophic levels (Benoit-Bird \& McManus 2012). Diel vertical migration of entire intense layers in TOTO suggests their importance in transferring energy from surface productive waters to the deep sea in this semi-enclosed ecosystem. We compared the heterogeneity of intense layers within TOTO to examine their effect on predator-prey dynamics between mesopelagic organisms and their predators. The midwaters of the West, East, and South zones are more energy-rich environments than the North zone, because of the frequent occurrence of strong, intense layers and large patches in the daytime DSLs. The West zone is further characterized by the highest occurrence and concentration of energy into thinner layers compared to the East and South zones. Hazen et al. (2011) observed higher $S_{\mathrm{v}} 38 \mathrm{kHz}$ values in daytime DSLs in the West than in the East zones. This is consistent with our observations, as intense layers dominate integrated acoustic measurements. These characteristics of patchiness may be important factors regulating foraging behavior of their predators including mesopelagic fishes and cephalopods, increasing the efficiency of foraging (Benoit-Bird \& McManus 2012, Benoit-Bird et al. 2013).

Heterogeneity of scattering layers has been recognized as an important mechanism for driving predator-prey dynamics in the ocean. Both physical processes and animal behavior contribute to the formation and maintenance of patchiness. Physical forcing structures the distribution of planktonic organ- 
isms (Steele 1976, Denman \& Powell 1984) and ultimately influences their predator distributions including zooplanktivorous fishes and seabirds (Kotliar \& Wiens 1990, Bertrand et al. 2014). Biological mechanisms can further magnify or modify physically induced spatial structures. Benoit-Bird \& Au (2003a,b) showed that multiple scales of patchiness of scattering layers dominated by micronekton can be a result of cooperative foraging behavior of their highlymobile marine mammal predators, altering the geometric and density characteristics of DSLs. In this study, the underlying mechanism driving the finescale variability of the intense layers remains unresolved. To develop an understanding of the relative importance of physical and biological forcing on structuring patchiness will require simultaneous measurements of physical characteristics within TOTO along with observations of the behavior of predator and prey.

Trophic levels connecting primary producers and top predators likely play a critical role in shaping the Bahamian ecosystem. While there were similar fluorescence values across TOTO, the high spatial variability in habitat usage by beaked whales in this region has been observed (McCarthy et al. 2011, Tyack et al. 2011, Claridge 2013). This study focused on the spatial variability of DSLs as they serve as a link between surface primary production and the deepwater fishes and cephalopods that serve as prey for beaked whales. A missing link in describing these food webs, however, is direct observations of the beaked whales' prey. Beaked whales forage at depths exceeding $800 \mathrm{~m}$ (Baird et al. 2006, Tyack et al. 2006), which is beyond the sampling limit of our ship-based acoustic observations. A recent study using an autonomous underwater vehicle equipped with echosounders has shown that heterogeneity of deepwater prey (>600 m) plays an important role in controlling preference for a different species of beaked whale off southern California, USA (BenoitBird et al. 2016); similar sampling was conducted as part of this effort and will extend our understanding of this study site in future analyses.

We observed that the spatial variability of the layer structures shaped the Bahamian mesopelagic ecosystem, potentially driving the variability of habitat use by top predators through their food resources. We suggest 2 potential mechanisms driving the Bahamian mesopelagic ecosystem by comparing common layer types observed within the sampling areas and zones. Differences between Abaco and TOTO were examined based on diffuse layer characteristics, focusing on the energy transfer between primary producers and mesopelagic organisms. The oceanographically connected habitat, Abaco, was characterized by diffuse layers made up of larger animals with greater migration distances and higher migrating biomass than TOTO, an oceanographically isolated habitat. Based on these observations, we hypothesize that Abaco may transfer more energy between energy-rich surface waters and the deep sea. The differences within TOTO were examined based on the heterogeneity of intense layers, focusing on their effect on predator-prey dynamics between mesopelagic organisms and their predators. The West, East, and South zones were more energy-rich ecosystems than the North zone based on the spatial variability in intense layers. Among those identified as energy-rich ecosystems, the habitat most frequently used by the beaked whales, the West zone, was characterized by the highest occurrence of intense, relatively thinner layers. Predators would benefit from consistently high biomass concentrated into a small space, increasing the efficiency of foraging (e.g. Benoit-Bird et al. 2013). Spatial variability of DSL structures and migration behavior reveals the dynamics of the Bahamian mesopelagic ecosystem, potentially driving the beaked whales' prey, and ultimately, the beaked whales themselves, through bottom-up control.

Acknowledgements. We thank the crew of the R/V 'Sharp' for field support. Chad Waluk provided technical expertise, assisted with equipment setup and data collection, and conducted pre-processing of the CTD and acoustic data. Marnie Jo Zirbel provided taxonomic expertise. Mark Moline, Brandon Southall, Chad Waluk, Ian Robbins, Diane Claridge, Charlotte Dunn, Megan Cimino, and Matthew Breece collaborated on the field operations. We thank 3 anonymous reviewers for their valuable comments which improved the focus of the manuscript. This work was funded by the Office of Naval Research Marine Mammal Biology Program (Grant Number: N00014-15-1-2204) to Kelly Benoit-Bird, Mark Moline, and Brandon Southall.

\section{LITERATURE CITED}

Abecassis M, Polovina J, Baird, RW, Copeland A and others (2015) Characterizing a foraging hotspot for short-finned pilot whales and Blainville's beaked whales located off the west side of Hawai'i Island by using tagging and oceanographic data. PLOS ONE 10:e0142628

Agawin NSR, Duarte CM, Agustí S (2000) Nutrient and temperature control of the contribution of picoplankton to phytoplankton biomass and production. Limnol Oceanogr 45:591-600

Ainslie MA, McColm JG (1998) A simplified formula for viscous and chemical absorption in sea water. J Acoust Soc Am 103:1671-1672

Anderson MJ (2001) A new method for non-parametric mul- 
tivariate analysis of variance. Austral Ecol 26:32-46

Ariza A, Landeira JM, Escánez A, Wienerroither R and others (2016) Vertical distribution, composition and migratory patterns of acoustic scattering layers in the Canary Islands. J Mar Syst 157:82-91

Armstrong JC (1953) Oceanography in the Tongue of the Ocean, Bahamas, B.W.I.: a report on oceanographic observations in the Tongue of the Ocean between Fresh Creek, Andros and the western end of New Providence. American Museum of Natural History, Dept of Fishes and Aquatic Biology, New York, NY

Ashjian CJ, Rosenwaks GA, Wiebe PH, Davis CS and others (2004) Distribution of zooplankton on the continental shelf off Marguerite Bay, Antarctic Peninsula, during austral fall and winter, 2001. Deep-Sea Res II 51: 2073-2098

Baird RW, Webster DL, McSweeney DJ, Ligon AD, Schorr GS, Barlow J (2006) Diving behaviour of Cuvier's (Ziphius cavirostris) and Blainville's (Mesoplodon densirostris) beaked whales in Hawai'i. Can J Zool 84: 1120-1128

Benoit-Bird KJ, Au WW (2003a) Prey dynamics affect foraging by a pelagic predator (Stenella longirostris) over a range of spatial and temporal scales. Behav Ecol Sociobiol 53:364-373

Benoit-Bird KJ, Au WW (2003b) Spatial dynamics of a nearshore, micronekton sound-scattering layer. ICES J Mar Sci 60:899-913

* Benoit-Bird KJ, Au WW (2004) Diel migration dynamics of an island-associated sound-scattering layer. Deep-Sea Res I 51:707-719

Benoit-Bird KJ, McManus MA (2012) Bottom-up regulation of a pelagic community through spatial aggregations. Biol Lett 8:813-816

Benoit-Bird KJ, Battaile BC, Heppell SA, Hoover B and others (2013) Prey patch patterns predict habitat use by top marine predators with diverse foraging strategies. PLOS ONE 8:e53348

Benoit-Bird KJ, Southall BL, Moline MA (2016) Predatorguided sampling reveals biotic structure in the bathypelagic. Proc R Soc B 283:20152457

* Bernal A, Olivar MP, Maynou F, de Puelles MLF (2015) Diet and feeding strategies of mesopelagic fishes in the western Mediterranean. Prog Oceanogr 135:1-17

* Bertrand A, Grados D, Colas F, Bertrand S and others (2014) Broad impacts of fine-scale dynamics on seascape structure from zooplankton to seabirds. Nat Commun 5:5239

Boehlert GW, Mundy BC (1988) Roles of behavioral and physical factors in larval and juvenile fish recruitment to estuarine nursery areas. Am Fish Soc Symp 3:51-67

Bost CA, Cotté C, Bailleul F, Cherel Y and others (2009) The importance of oceanographic fronts to marine birds and mammals of the southern oceans. J Mar Syst 78:363-376

Choy CA, Portner E, Iwane M, Drazen JC (2013) Diets of five important predatory mesopelagic fishes of the central North Pacific. Mar Ecol Prog Ser 492:169-184

Claridge DE 2013. Population ecology of Blainville's beaked whales (Mesoplodon densirostris). PhD thesis, University of St Andrews

Cohen JH, Forward RB (2016) Zooplankton diel vertical migration-a review of proximate control. Oceanogr Mar Biol Annu Rev 47:77-110

Cox TM, Ragen TJ, Read AJ, Vos E and others (2006) Understanding the impacts of anthropogenic sound on beaked whales. J Cetacean Res Manag 7:177-187
Davison PC, Koslow JA, Kloser RJ (2015) Acoustic biomass estimation of mesopelagic fish: backscattering from individuals, populations, and communities. ICES J Mar Sci 72:1413-1424

*De Robertis A, Higginbottom I (2007) A post-processing technique to estimate the signal-to-noise ratio and remove echosounder background noise. ICES J Mar Sci 64:1282-1291

* De Robertis A, Jaffe JS, Ohman MD (2000) Size-dependent visual predation risk and the timing of vertical migration in zooplankton. Limnol Oceanogr 45:1838-1844

Demer DA, Berger, L, Bernasconi M, Bethke E and others (2015) Calibration of acoustic instruments. ICES Coop Res Rep 326:1-133

Denman KL, Powell TM (1984) Effects of physical processes on planktonic ecosystems in the coastal ocean. Oceanogr Mar Biol Annu Rev 22:125-168

₹ Duffy E, Paul J, Richardson J, France KE (2005) Ecosystem consequences of diversity depend on food chain length in estuarine vegetation. Ecol Lett 8:301-309

* Fernández A, Edwards JF, Rodriguez F, De Los Monteros AE and others (2005) 'Gas and fat embolic syndrome' involving a mass stranding of beaked whales (Family Ziphiidae) exposed to anthropogenic sonar signals. Vet Pathol 42:446-457

*Hannides CC, Landry MR, Benitez-Nelson CR, Styles RM, Montoya JP, Karl DM (2009) Export stoichiometry and migrant-mediated flux of phosphorus in the North Pacific Subtropical Gyre. Deep-Sea Res I 56:73-88

*Hazen EL, Johnston DW (2010) Meridional patterns in the deep scattering layers and top predator distribution in the central equatorial Pacific. Fish Oceanogr 19:427-433

*Hazen EL, Nowacek DP, St. Laurent L, Halpin PN, Moretti DJ (2011) The relationship among oceanography, prey fields, and beaked whale foraging habitat in the Tongue of the Ocean. PLOS ONE 6:e19269

Hickmott LS 2005. Diving behaviour and foraging ecology of Blainville's and Cuvier's beaked whales in the northern Bahamas. MSc thesis, University of St Andrews

* Irigoien X, Klevjer TA, Røstad A, Martinez U andothers, (2014) Large mesopelagic fishes biomass and trophic efficiency in the open ocean. Nat Commun 5:3271

Isaacs JD, Kidd LW (1953) Issacs-Kidd midwater trawl final report. SIO Oceanogr Equip Rep 1:1-21

Kaartvedt S, Staby A, Aksnes DL (2012) Efficient trawl avoidance by mesopelagic fishes causes large underestimation of their biomass. Mar Ecol Prog Ser 456:1-6

Karuppasamy PK, Menon NG (2004) Food and feeding habits of the pelagic shrimp, Oplophorus typus from the deep scattering layer along the west coast of India. Indian J Fish 51:17-20

Karuppasamy PK, Menon NG, Nair KKC, Achuthankutty CT (2006) Distribution and abundance of pelagic shrimps from the deep scattering layer of the eastern Arabian Sea. J Shellfish Res 25:1013-1019

Kotliar NB, Wiens JA (1990) Multiple scales of patchiness and patch structure: a hierarchical framework for the study of heterogeneity. Oikos 59:253-260

K Leaman KD, Vertes PS, Atkinson LP, Lee TN, Hamilton P, Waddell E (1995) Transport, potential vorticity, and current/temperature structure across Northwest Providence and Santaren Channels and the Florida Current off Cay Sal Bank. J Geophys Res 100:8561-8569

Legendre L, Le Fevre J (1991) From individual plankton cells to pelagic marine ecosystems and to global biogeo- 
chemical cycles. In: Demers S (ed) Particle analysis in oceanography. Springer, Berlin, p 261-300

Longhurst AR (1976) Vertical migration In: Cushing DH, Walsh JJ (eds)The ecology of the seas. W. B. Saunders, Philadelphia, PA, p 116-137

Mackenzie KV (1981) Nine-term equation for sound speed in the oceans. J Acoust Soc Am 70:807-812

Marañón E, Holligan PM, Barciela R, González N, Mouriño B, Pazó MJ, Varela M (2001) Patterns of phytoplankton size structure and productivity in contrasting open-ocean environments. Mar Ecol Prog Ser 216:43-56

Mauchline J (1980a) Measurement of body length of Euphausia superba Dana. BIOMASS Handbook, No. 4, p 4-9

Mauchline J (1980b) The biology of mysids and euphausiids. Adv Mar Biol 18:1-677

McCarthy E, Moretti D, Thomas L, DiMarzio N and others (2011) Changes in spatial and temporal distribution and vocal behavior of Blainville's beaked whales (Mesoplodon densirostris) during multiship exercises with midfrequency sonar. Mar Mamm Sci 27:E206-E226

Methot RD (1986) Frame trawl for sampling pelagic juvenile fish. CCOFI Rep 27:267-278

Moline MA, Claustre H, Frazer TK, Schofield O, Vernet M (2004) Alteration of the food web along the Antarctic Peninsula in response to a regional warming trend. Glob Change Biol 10:1973-1980

Moretti D, DiMarzio N, Morrissey R, Ward J, Jarvis S (2006) Estimating the density of Blainville's beaked whale (Mesoplodon densirostris) in the Tongue of the Ocean (TOTO) using passive acoustics. Proceedings of IEEE OCEANS 2006 Conference, Boston, MA, p 1-5

Nigmatullin CM, Nesis KN, Arkhipkin AI (2001) A review of the biology of the jumbo squid Dosidicus gigas (Cephalopoda: Ommastrephidae). Fish Res 54:9-19

Pace ML, Cole JJ, Carpenter SR, Kitchell JF (1999) Trophic cascades revealed in diverse ecosystems. Trends Ecol Evol 14:483-488

Paine RT (1966) Food web complexity and species diversity. Am Nat 100:65-75

* Pauly D, Christensen V (1995) Primary production required to sustain global fisheries. Nature 374:255-257

Podeswa Y, Pakhomov EA (2015) Feeding ecology of pelagic decapods in the North Pacific Subtropical gyre: implications for active carbon transport. Arthropoda Sel 24: 317-334

Polis GA, Anderson WB, Holt RD (1997) Toward an integration of landscape and food web ecology: the dynamics of spatially subsidized food webs. Annu Rev Ecol Syst 28: 289-316

Post DM (2002) The long and short of food-chain length. Trends Ecol Evol 17:269-277

Editorial responsibility: Marsh Youngbluth, Fort Pierce, Florida, USA
Rogers AD (1994) The biology of seamounts. Adv Mar Biol 30:305-350

Santos MB, Pierce GJ, Herman J, López A, Guerra A, Mente E, Clarke MR (2001) Feeding ecology of Cuvier's beaked whale (Ziphius cavirostris): a review with new information on the diet of this species. J Mar Biol Assoc UK 81: 687-694

Sato M, Dower JF, Kunze E, Dewey R (2013) Second-order seasonal variability in diel vertical migration timing of euphausiids in a coastal inlet. Mar Ecol Prog Ser 480: 39-56

Seki MP, Polovina JJ, Kobayashi DR, Bidigare RR, Mitchum GT (2002) An oceanographic characterization of swordfish (Xiphias gladius) longline fishing grounds in the springtime subtropical North Pacific. Fish Oceanogr 11: 251-266

* Shroyer EL, Benoit-Bird KJ, Nash JD, Moum JN (2014) Stratification and mixing regimes in biological thin layers over the Mid-Atlantic Bight. Limnol Oceanogr 59:1349-1363

Simmonds J, MacLennan DN 2005. Fisheries acoustics: theory and practice, 2nd edn. Blackwell Science, Oxford

Steele JH (1976) Patchiness. In: Cushing DH, Walsh JJ (eds) The ecology of the seas. Blackwell Scientific, Philadelphia, PA, p 98-115

Steinberg DK, Lomas MW, Cope JS (2012) Long-term increase in mesozooplankton biomass in the Sargasso Sea: linkage to climate and implications for food web dynamics and biogeochemical cycling. Global Biogeochem Cycles 26

Tyack PL, Johnson M, Soto NA, Sturlese A, Madsen PT (2006) Extreme diving of beaked whales. J Exp Biol 209: 4238-4253

Tyack PL, Zimmer WMX, Moretti D, Southall BL and others (2011) Beaked whales respond to simulated and actual navy sonar. PLOS ONE 6:e17009

W Ware DM, Thomson RE (2005) Bottom-up ecosystem trophic dynamics determine fish production in the Northeast Pacific. Science 308:1280-1284

Wilson PA, Roberts HH (1995) Density cascading: off-shelf sediment transport, evidence and implications, Bahama Banks. J Sediment Res 65:45-56

*Wroblewski JS (1982) Interaction of currents and vertical migration in maintaining Calanus marshallae in the Oregon upwelling zone - a simulation. Deep-Sea Res A 29: 665-686

พ Young JW, Bradford R, Lamb TD, Clementson LA, Kloser R, Galea H (2001) Yellowfin tuna (Thunnus albacares) aggregations along the shelf break off south-eastern Australia: links between inshore and offshore processes. Mar Freshw Res 52:463-474

Submitted: March 20, 2017; Accepted: August 3, 2017

Proofs received from author(s): September 17, 2017 